\title{
Determinants of food security and availability of healthy and safe nutrition - food security of children in rural Punjab, India
}

\author{
Kavita Sharma ${ }^{1, *}$, Sachin Sharma ${ }^{2}$, and Deepak Sood ${ }^{3}$ \\ ${ }^{1}$ University School of Business, Chandigarh University, Mohali, Punjab, India \\ ${ }^{2}$ School of Management Studies, CT University, Ludhiana, Punjab, India \\ ${ }^{3}$ Chitkara Business School, Chitkara University, Punjab, India
}

\begin{abstract}
It is critical to ensure that the availability of food, as well as food safety, are preserved in food security systems. This has substantial consequences on the health of world's population. Food safety deals with food-borne disease, and it focuses on how, where, and what food is handled, prepared, and stored. The healthiness of a diet depends on the nutritional quality of its food. Food security is a multifaceted concept that takes into account several issues and projects throughout the globe. The findings from this study are intended to provide insight into the food security of children in rural Punjab, India. To study the possibility to establish sustainable programmes that assure hot meals for school students in rural Punjab, the primary goal of the research is to do so. Researchers in Punjab have not done any equivalent scholarly study focusing on food security from an economic standpoint. In-depth nondirective interviews were used to find out what experienced professionals thought. The findings reveal the need to increase family and school food resources to meet the nutritional requirements of children in rural regions. Additionally, offering hot meals in primary schools in impoverished communities is justifiable since poor nutrition among school-aged children has both short-term and long-term impacts on their academic success and development. These findings lead to management implications for policy makers who want to measure the effectiveness of national and state funded educational programmes.
\end{abstract}

\section{Introduction}

Aspects of food systems that impact public health include food security, food safety, and nutrition[1]. For a healthy diet, a combination of foods must be selected that provides all essential nutrients, whether of whether the individual is underweight or overweight[2]. Food safety is concerned with food-borne disease, and food handling, preparation, and storage are all aspects that fall under this concern[3]. When the United Nations Food and Agriculture Organization (FAO) refers to "food security, they mean a situation in which everyone has the resources they need to acquire enough food to ensure that they have physical, social, and economic access to sufficient, safe, and nutritious food to satisfy their dietary needs and food

\footnotetext{
*Corresponding author: kavita.e10427@cumail.in
} 
preferences."[4]The four pillars of food security described by the FAO contain not only food safety and proper nutrition, but also incorporate other problems relating to food supply, accessibility, use, and stability[5]. Nevertheless, strife exists between food safety, proper nutrition, and food security, each of which has a different definition[6].

The goals, however, are very difficult to accomplish in reality[8]. They are inherently political, as well as technical[6]. These three issues entail choices that are taken by both national governments and international organisations as well as by individual nations[9].

\section{Methods}

The study's goal is to investigate food security in rural settings for children. Participants were selected based on the idea that they are most likely to have knowledge that is useful to the situation. The majority of these people have a daily involvement in the educational process through helping with the instruction of rural school children. They can see how children's educational choices are impacted by the environments they grow up in, including foodstuffs. Additionally, the interviewers have developed a level of understanding to measure the program's effects on the intended target population. The people interviewed were all experts, as well as professionals in the fields of psychology, medicine, nursing, physical education, and teaching. A panel of 16 persons were interviewed to make a decision. They provide health education, frequent health assessments, and counselling designed to help youngsters build self-esteem. 150 children were monitored at this phase of the study: of the children between the ages of 3 to 5, 269 were enrolled in the kindergartens and schools included in the research, and 231 were between the ages of 6 and 14. Figure 1 depicted the four strong pillars of food security and base of nutritional level.

For the research, the educational units in which the work was done are located as follows (Table 1):

Table 1. Name of a village in Punjab - State name

\begin{tabular}{|c|c|c|}
\hline S.No. & Name of Village in Punjab & Name of the State \\
\hline 1. & Bagga & Amritsar \\
\hline 2. & Danewal & Jalandhar \\
\hline 3. & Goslan & Ludhiana \\
\hline 4. & Alampur & Hoshiarpur \\
\hline
\end{tabular}

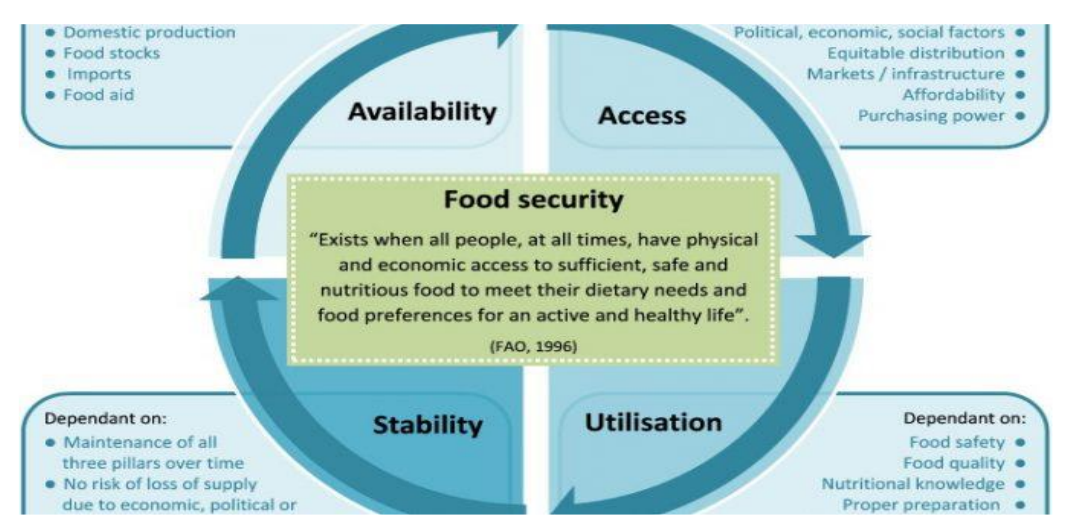

Fig 1. Model of Pillars of Food Security and Nutritional Base 


\section{Results and Discussion}

The data shown in Table 2 include the findings of the KMO and Bartlett test of sphericity, which were crucial in proving the validity of component analysis. A measure of sample size adequacy is provided by the Kaiser-Meyer-Olkin (KMO) test, which uses two observed variables to analyse a third observed variable. A sample of 650 people was utilised in the research, which is big enough for statistical analysis to be skipped, but the outcomes of the Bartlett test of sphericity are also available which found to be significant.The use of KMO test statistics serves the purpose of evaluating a wide range of values, from 0 to $1 \mathrm{KMO}$ test is producing a result with an accuracy of more than $0.50(n=.914$ in case of existing KMO output), as value rises, outcomes improve. After doing a statistical analysis, the findings proved that the sample size was adequate and that the variables showed a strong association in order to construct the factors.

Table 2. KMO and Bartlett's Test

\begin{tabular}{|l|c|c|}
\hline \multicolumn{3}{|c|}{ KMO and Bartlett's Test } \\
\hline Kaiser-Meyer-Olkin Measure of Sampling Adequacy. & .914 \\
\hline Bartlett's Test of Sphericity & Approx. Chi-Square & 3662.247 \\
\cline { 2 - 3 } & Df & 105 \\
\cline { 2 - 3 } & Sig. & .000 \\
\hline
\end{tabular}

Source: Computed Data

The table 3 displays the factors retrieved by use of a method known as factor analysis, as well as the factor loading for each variable. Using PCA to extract four components and using varimax rotation allowed the highest amount of variation in the data to be explained. Of the overall variation, the four variables explained 74.44 percent. A substantial amount of information was lost through this data reduction procedure, reducing the variance to 25.56 percent.Eigenvalues describe the variation that each component accounts for. $22.61 \%$ of the variation in the data was explained by the first component (Availability), with $21.88 \%$ explained by the second component (Accessibility). $17.43 \%$ and $12.5 \%$ of variation were explained by the third and fourth independent variables, respectively. This combination of four variables contributed to $74.44 \%$ of the variation, exceeding the $60 \%$ criterion. Therefore, it may be inferred that the effective and logical reduction of 15 variables to four components was reached. the four primary elements provide good explanations for the effects of many variables on food security and the availability of safe and healthful nourishment. Since loadings of factors below 0.4 were not deemed significant, these results have been suppressed. "Availability" was shown to have four factors directly connected to it, as shown by the results. Factor loading was .659 and .606 , respectively, when applied to the sample population. There were three factors whose variables were seen to influence 'Accessibility' - and these were the second and third factors. Factor loadings (the first and last numbers) were set at .721 and .652 respectively. There were four observed variables under the third category, which is called "Utilization." The fourth component, which was labelled "Stability," comprised of four variables, all of which had loadings under .659 and above .606. 
Table 3. Factor Loadings (Rotated Component Matrix)

\begin{tabular}{|l|c|c|c|c|}
\hline \multicolumn{1}{|c|}{ Dimensions of food security } & Availability & Accessibility & Utilization & Stability \\
\hline Domestic production & 0.628 & & & \\
\hline Import capacity & 0.659 & & & \\
\hline Food stocks & 0.606 & & & \\
\hline Food aid pown, own & & & & \\
\hline $\begin{array}{l}\text { Income, purchasing power, } \\
\text { production }\end{array}$ & & 0.656 & & \\
\hline Transport and market infrastructure & & 0.721 & & \\
\hline Food distribution quality & & 0.703 & & \\
\hline Food safety and qualy & & & 0.632 & \\
\hline Clean water & & & 0.623 & \\
\hline Health and sanitation & & & 0.502 & \\
\hline $\begin{array}{l}\text { Care, feeding and health seeking } \\
\text { practices }\end{array}$ & & & 0.424 & \\
\hline Weather variability, seasonality & & & & 0.628 \\
\hline Price fluctuations & & & & 0.659 \\
\hline Political factors & & & & 0.606 \\
\hline Economic factors & & & & 0.628 \\
\hline
\end{tabular}

Extraction Method: Principal Component Analysis. Rotation Method: Varimax with Kaiser Normalization. Rotation converged in 15 iterations

Source: Computed Data

\subsection{Confirmatory Factor Analysis (CFA)}

In the following phase, it is absolutely necessary to determine whether or not factors are linked to their variables. Measurement-item quality is first evaluated in the confirmatory technique, and then the measurement model is calculated to show the accuracy of the items. The construct displays the link between observed variables in a measurement model. The PLS methodology is used to evaluate the model due to the many variables in the mode, and it is possible to evaluate all relationships using the PLS at the same time.

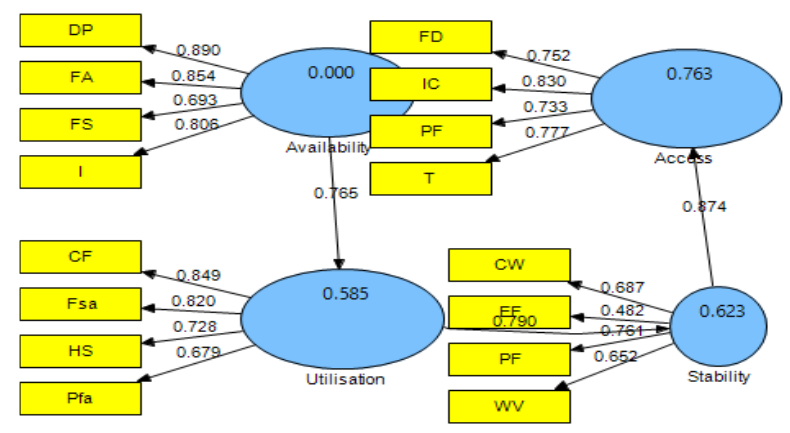

Fig 2. Partial least squares

See Table 4 for an illustration of the structure of the measurement model. The factor loadings are almost identical to the EFA's results. In confirmatory factor analysis, factor loadings are permitted that are greater than those permitted in exploratory factor analysis. The loadings are more than 0.7 (except one). Beyond 0.7, loadings above that threshold are regarded acceptable, and show an acceptable model fit overall. If the factor loadings were 
over 0.7 , it meant that the model had strong convergent validity. Other goodness parameters may be considered acceptable as long as the measurement model converges.

Table 4. Factor loadings of measurement model

\begin{tabular}{|l|l|c|c|c|c|}
\hline Variables/Factors & & Availability & Accessibility & Utilization & Stability \\
\hline Domestic production & DP & 0.715 & 0.8903 & 0.7674 & 0.7429 \\
\hline Import capacity & IC & 0.8296 & 0.6861 & 0.6561 & 0.6984 \\
\hline Food stocks & FS & 0.5176 & 0.6935 & 0.5458 & 0.5087 \\
\hline Food aid & FA & 0.7435 & 0.8544 & 0.7242 & 0.6909 \\
\hline $\begin{array}{l}\text { Income, purchasing power, } \\
\text { own production }\end{array}$ & I & 0.7435 & 0.8544 & 0.7242 & 0.6909 \\
\hline $\begin{array}{l}\text { Transport and market } \\
\text { infrastructure }\end{array}$ & $\mathrm{T}$ & 0.7774 & 0.6817 & 0.6097 & 0.5146 \\
\hline Food distribution & FD & 0.7519 & 0.5238 & 0.6502 & 0.637 \\
\hline Food safety and quality & FS & 0.5176 & 0.6935 & 0.5458 & 0.5087 \\
\hline Clean water & CW & 0.5303 & 0.7267 & 0.6868 & 0.6994 \\
\hline Health and sanitation & $\mathrm{HS}$ & 0.5223 & 0.7244 & 0.5945 & 0.7275 \\
\hline $\begin{array}{l}\text { Care, feeding and health } \\
\text { seeking practices }\end{array}$ & $\mathrm{CF}$ & 0.5421 & 0.5019 & 0.6142 & 0.8487 \\
\hline $\begin{array}{l}\text { Weather variability, } \\
\text { seasonality }\end{array}$ & $\mathrm{WV}$ & 0.5575 & 0.5791 & 0.6522 & 0.5565 \\
\hline Price fluctuations & $\mathrm{PF}$ & 0.7329 & 0.673 & 0.761 & 0.4333 \\
\hline Political factors & $\mathrm{PFa}$ & 0.4939 & 0.5062 & 0.5737 & 0.6794 \\
\hline Economic factors & $\mathrm{EF}$ & 0.4446 & 0.1564 & 0.4815 & 0.3284 \\
\hline
\end{tabular}

Source: Computed Data

\subsection{Reliability and validity of factors}

Building on the previous stage, it is crucial to confirm the model's dependability and validity. Cronbach's alpha measures the dependability of the factors. When administering the Cronbach test, we presume that the statements we are administering all assess the same construct (i.e., the construct is unidimensional), and that observations are independent of each other.The findings from Cronbach's alpha are seen in Table 4. Cronbach's alpha values were found to be between .69 and .829 , which are very satisfactory.

Composite reliability is another and superior measure of dependability (CR). When the weights used in estimate of a construct are based on the factor scores, then it is regarded to be superior than Cronbach's alpha. The minimum acceptable value of $\mathrm{CR}$ is somewhere between .7 and 1 . The value of $\mathrm{CR}$ for a construct should be bigger than 0.7 . All four constructions have $\mathrm{CR}$ values larger than 0.7 in table 5. In composite reliability, the lowest recorded CR was 0.797 .

Table 5. Reliability and convergent validity statistics of measurement model

\begin{tabular}{|c|c|c|c|c|}
\hline Factor & $\begin{array}{c}\text { Number of } \\
\text { items }\end{array}$ & $\begin{array}{c}\text { Cronbach's } \\
\text { alpha }\end{array}$ & $\begin{array}{c}\text { Average variance } \\
\text { extracted }\end{array}$ & $\begin{array}{c}\text { Composite } \\
\text { reliability }\end{array}$ \\
\hline Availability & 5 & 0.7764 & 0.5988 & 0.8562 \\
\hline Accessibility & 3 & 0.829 & 0.6631 & 0.8865 \\
\hline Utilization & 4 & 0.5448 & 0.427 & 0.7441 \\
\hline Stability & 4 & 0.7703 & 0.5958 & 0.854 \\
\hline
\end{tabular}

Source: Computed Data 
Table 6, indicated that Stability (mean $=4.42$, std dev $=.643$ ) found to be the most influencing determinant for food security and availability of healthy nutrition for the rural children residing in Punjab villages.

Table 6. Descriptive statistics of food security

\begin{tabular}{|l|l|l|l|c|c|c|}
\hline \multicolumn{6}{|c|}{ Descriptive Statistics } \\
\hline & \multicolumn{1}{|c|}{$\mathrm{N}$} & Minimum & Maximum & Mean & Std. Deviation \\
\hline Availability & 650 & 1 & 5 & 4.33 & .660 \\
\hline Accessibility & 650 & 1 & 5 & 4.38 & .648 \\
\hline Utilization & 650 & 1 & 5 & 4.35 & .728 \\
\hline Stability & 650 & 1 & 5 & 4.42 & .643 \\
\hline Valid N (listwise) 650 & & & & \\
\hline
\end{tabular}

Source: Computed Data

\section{Conclusion}

The article above explains how, despite seeming conflict, the three characteristics of healthy food systems are not only compatible but also complimentary in nature, since each is an essential purpose and result of strong food systems[10]. To put it another way, in reality, their compatibility is much reduced. To provide another example, governments generally place more importance on securing food security and food safety above optimal nutrition, even though these trade-offs may vary based on local and regional settings[11]. When it comes to researching and promoting food systems, researchers and advocates must deal with finding new and creative methods to better connect proper nutrition to food security and food safety, while also raising the issue's accessibility from a political standpoint[12]. This addresses the issue of food security and food safety, both of which contribute to improved nutrition in food systems that are both healthy and sustainable[13].

\section{References}

1. R. K. Talukder, F. Alam, M. Islam, Plan. Communication (2015)

2. A. Bhatia, P. Agarwal, E. Neena, A. Mehla, N. Makhijani, Assessment of Health, Hygiene and Nutritional status of Migrant Labourers: Scientific Intervention and Community Participation (2014)

3. F. A. Khalid, J. Ethn. Foods, 4(3), 181 (2017)

4. M. Ningying, MOJ Public Health., 7(4), 196 (2018)

5. W. Peng, E. M. Berry, Encycl. Food Secur. Sustain., 1 (2018)

6. D. Barclay, F. Haschke, World Rev. Nutr. Diet., 111, 198 (2015)

7. K. Havas, M. Salman, Int. J. Food Safety, Nutr. Public Heal., 4(1), 4 (2011)

8. H. Ghattas, FAO, Food Agric. Organ. United Nations, 1 (2014)

9. M. Tiwari, S. Babel, J. Appl. Nat. Sci., 5(2), 416 (2013)

10. H. El Bilali, C. Callenius, C. Strassner, L. Probst, Food Energy Secur., 8(2), 1 (2019)

11. H. Walls, P. Baker, E. Chirwa, B. Hawkins, Glob. Food Sec., 21, 69 (2019)

12. I. Vågsholm, N. S. Arzoomand, S. Boqvist, Front. Sustain. Food Syst., 4, 1 (2020)

13. A. S. Tecau, C. Dimitriu, N. Marinescu, B. Tescasiu, G. Epuran, Sustain., 12(21), 1 (2020) 